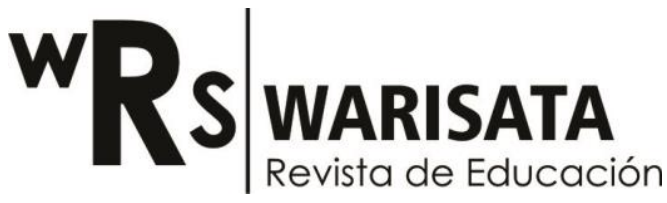 \\ CURRículo de AuTORES
}

\section{Maigualida Bejas}

Doctora en Ciencias Políticas, con maestría en Geografía, mención Docencia. Licenciada en Educación, mención Ciencias Sociales de la Universidad del Zulia. Ha publicado en diversas editoriales. Es Tutora en las líneas de investigación: Educación, gerencia educativa, comunidades, ciudadanía y geografía.

$$
\text { (ต) งंอ }
$$

\section{Yesenia Bonilla}

Licenciada en Educación Integral, Mención Docencia en inglés como lengua extranjera. Formación en docencia de español como lengua extranjera. Maestra de aula de 4to grado en un colegio público de Denver, Co. Miembro de Ventesol (Venezuelan Teachers of English to students of others languages)

$$
\text { () ตंอ อ }
$$

\section{Aimara Esco6ar}

Socióloga. Profesora Instructora de la Escuela de Educación de la Universidad Central de Venezuela (UCV). Coordinadora de Gestión y Planificación Académica en la Dirección de Postgrado de la Universidad Nacional Experimental de la Seguridad (UNES), Venezuela.

\section{Yelena Montesino}

Profesional en Psicología Social Comunitaria. Especialista en Lúdica Educativa. Magister en Ciencias de la Educación. Docente con funciones de Orientadora en la Institución Educativa Rafael Uribe Uribe, Colombia.

$$
\text { ๑) ตंอ อ }
$$

\section{Claudia Salinas}

Licenciada en Ciencias Sociales y Económicas de la Universidad del Atlántico, Colombia. Magister en Gerencia de organizaciones educativas, Universidad del Zulia, Venezuela. Actualmente coordinadora integral en la Escuela Normal Superior del Distrito de Barraquillas.

$$
\text { ๑) ๑ंอ }
$$

